\title{
A Literature Review Of Deterministic Stability of a System of Nonlinear First Order Ordinary Differential Equations: Theory and Application in Agriculture
}

\author{
${ }^{1}$ E. N. Ekaka-A, ${ }^{2}$ V. E. Asor, ${ }^{3}$ N. E. S. Lale, ${ }^{4}$ C. C. Wokocha, \\ ${ }^{5}$ N. M. Nafo, ${ }^{6}$ A. Weli, ${ }^{7}$ E.H. Amadi, ${ }^{8}$ E.C. Nwachukwu, \\ ${ }^{1,5,6,7}$ Department Of Mathematics and Computer Science, Rivers State University Of Science And \\ Technology, Port Harcourt, Nigeria. \\ ${ }^{2,8}$ Department Of Mathematics and Statistics, Faculty Of Physical Scences And Information Science, \\ University Of Port Harcourt, Port Harcourt, Nigeria. \\ ${ }^{3,4}$ Department Of Crop And Soil Science, Faculty Of Agriculture, University Of Port Harcourt,Port \\ Harcourt, Nigeria.
}

Abstract. In this work, the deterministic model which describes the dynam-ics of interaction between two legumes has been defined. The motivation and benefits of stabilizing this system of complex model equations of continuous nonlinear first order ordinary differential equations in the field of agriculture has been clearly well posed. We will expect this pioneering research to form a bench mark collaboration between modellers and crop science experts.

Keywords: and phrases. Steady-State Solutions, Stability, Legumes.

\section{Introduction:}

Theoretical Perspectives of Stabilization

In this section, we will consider the theoretical perspective of the theory of stabilizing unstable steady-state solution ([5]).

Consider the following system of continuous nonlinear first order ordinary dif- ferential equation:

$$
\begin{aligned}
& \frac{d y}{d t}=y(t)\left(a_{1}-b_{1} y(t)-c_{1} z(t)\right), \\
& \frac{d z}{d t}=z(t)\left(a_{2}-b_{2} z(t)-c_{2} y(t)\right),
\end{aligned}
$$

where $\mathrm{y}(0)=\mathrm{y}_{0}>0, \mathrm{z}(0)=\mathrm{z} 0>0$. Here $\mathrm{a} \mathbf{i}, \mathrm{b}_{\mathbf{i}}, \mathrm{c}_{\mathbf{i}}, \mathbf{i}=1,2$ are positive constants.

The steady states $\left(\mathrm{ye}_{\mathrm{e}}, \mathrm{ze}_{\mathrm{e}}\right)$ satisfy

(1.3) (1.4)

$\mathrm{ye}_{\mathrm{e}}\left(\mathrm{a}_{1}-\mathrm{b}_{1} \mathrm{ye}_{\mathrm{e}}-\mathrm{c}_{1} \mathrm{z}_{\mathrm{e}}\right)=0, \mathrm{ye}_{\mathrm{e}}\left(\mathrm{a}_{2}-\mathrm{b}_{2} \mathrm{ye}_{\mathrm{e}}-\mathrm{c}_{2} \mathrm{z}_{\mathrm{e}}\right)=0$.

Four steady states

$\mathrm{y}_{\mathrm{e}}=0, \quad \mathrm{z}_{\mathrm{e}}=0$,

$$
\begin{aligned}
& \mathrm{y}=0, \quad \mathrm{z}=\frac{\mathrm{a} 2}{\mathrm{e}}, \\
& \mathrm{e}
\end{aligned}
$$

$\mathrm{y}={ }^{\mathrm{a}} 1$

e $b_{1}$

,$- \mathrm{ze}_{\mathrm{e}}=0$,

$a_{1} c_{2}-c_{1} a_{2}$

$\mathrm{ye}=$

12

$$
\frac{b_{c}-c_{1} b_{2},}{z_{2}}=\frac{b_{1} a_{2}-a_{1} b_{2}}{b_{c}-c_{1} b_{2}}
$$

Question: How do we stabilize $\left(\mathrm{ye}_{\mathrm{e}}, \mathrm{ze}_{\mathrm{e}}\right)$ if $\left(\mathrm{ye}_{\mathrm{e}}, \mathrm{ze}_{\mathrm{e}}\right)$ is unstable? 
Denote

\section{Linearized system about (ye, ze )}

$$
\mathrm{F}(\mathrm{y}, \mathrm{z})=\mathrm{y}(\mathrm{a} 1-\mathrm{b} 1 \mathrm{y}-\mathrm{c} 1 \mathrm{z}) \cdot \mathrm{G}(\mathrm{y}, \mathrm{z})=\mathrm{z}\left(\mathrm{a}_{2}-\mathrm{b}_{2} \mathrm{y}-\mathrm{c} 2 \mathrm{z}\right)
$$

dy

Consider the system

$$
\begin{aligned}
& \underset{\mathrm{dz}}{=} \mathrm{F}(\mathrm{y}, \mathrm{z}), \mathrm{dt} \\
& \quad-=\mathrm{G}(\mathrm{y}, \mathrm{z}) .
\end{aligned}
$$

dt

Taylor expansion about (ye, ze),

$$
\begin{aligned}
& \mathrm{F}(\mathrm{y}, \mathrm{z})=\mathrm{F}\left(\mathrm{ye}_{\mathrm{e}}, \mathrm{ze}_{\mathrm{e}}\right)+ \\
& +\partial \mathrm{F}\left(\mathrm{ye}_{\mathrm{e}}, \mathrm{z}_{\mathrm{e}}\right) \\
& \partial \mathrm{z} \\
& \mathrm{G}(\mathrm{y}, \mathrm{z})=\mathrm{G}\left(\mathrm{ye}_{\mathrm{e}}, \mathrm{ze}_{\mathrm{e}}\right)+ \\
& +\partial \mathrm{G}\left(\mathrm{ye}_{\mathrm{e}}, \mathrm{z}_{\mathrm{e}}\right) \\
& \frac{\partial \mathrm{F}\left(\mathrm{ye}, \mathrm{ze}_{\mathrm{e}}\right)}{\partial \mathrm{y}}(\mathrm{y}-\mathrm{y}) \\
& \begin{array}{l}
\partial y \\
\left(z-z_{e}\right)+\text { higher-order-terms, }
\end{array} \\
& \partial \mathrm{z}
\end{aligned}
$$

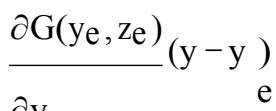

$$
\begin{aligned}
& \partial y \\
& \left(z-z_{e}\right)+\text { higher-order-terms. }
\end{aligned}
$$$$
\text { Linearized system about (ye, ze) }
$$$$
\text { The linearized systems about }\left(\mathrm{ye}_{\mathrm{e}}, \mathrm{ze}\right) \text { are }
$$$$
\mathrm{dy}=\partial \mathrm{F}\left(\mathrm{ye}_{\mathrm{e}}, \mathrm{z}_{\mathrm{e}}\right)
$$$$
\mathrm{dt}
$$$$
\mathrm{dz} \quad \partial \mathrm{G}\left(\mathrm{ye}, \mathrm{ze}_{\mathrm{e}}\right)
$$$$
\mathrm{dt}
$$$$
\begin{array}{r}
\frac{}{\partial \mathrm{y}}\left(\mathrm{y}-\mathrm{ye}_{\mathrm{e}}\right)+\frac{\partial \mathrm{F}\left(\mathrm{ye}_{\mathrm{e}}, \mathrm{ze}_{\mathrm{e}}\right)}{\partial \mathrm{z}}\left(\mathrm{z}-\mathrm{ze}_{\mathrm{e}}\right), \\
\left.-\frac{\partial \mathrm{G}\left(\mathrm{ye}_{\mathrm{e}}, \mathrm{z}_{\mathrm{e}}\right.}{\partial \mathrm{y}}\left(\mathrm{y}-\mathrm{ye}_{\mathrm{e}}\right)+\mathrm{z}_{\mathrm{z}}\right) .
\end{array}
$$

Substituting $\mathrm{y}-\mathrm{ye}$ and $\mathrm{z}-\mathrm{ze}$ by $\mathrm{Y}$ and $\mathrm{Z}$ seperately and denoting

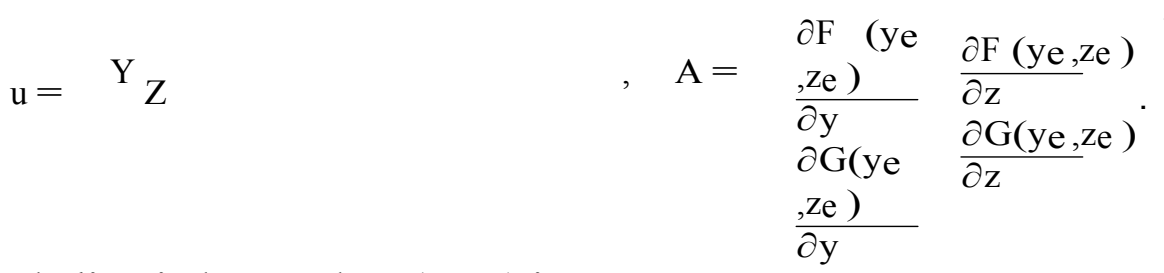

The linearized system about $\left(\mathrm{ye}, \mathrm{ze}_{\mathrm{e}}\right)$ is

$\mathrm{du}$

$$
\overline{\mathrm{dt}}=\mathrm{Au}, \quad \mathrm{u}(0)=\mathrm{u} 0
$$

where

$\mathrm{u} 0=$

y0 - ye $\quad z_{0}-z_{e}$ 


\section{Stability of the steady states}

Lemma 3.1. Assume that all the eigenvalues of $\mathrm{A}$ are negative, then the solution of equation (9) tends to the steady state $\left(\mathrm{ye}_{\mathrm{e}}, \mathrm{ze}_{\mathrm{e}}\right)$ as $\mathrm{t} \rightarrow \infty$ for some suitable initial value $\mathrm{u}_{0}=\left(\mathrm{y}_{0}-\mathrm{ye}_{\mathrm{e}}, \mathrm{z}_{0}-\mathrm{ze}_{\mathrm{e}}\right)$.

- If A has a positive eigenvalue, then the steady state (ye, $\left.\mathrm{ze}_{\mathrm{e}}\right)$ is not stable.

- We will use the feedback control to stabilize the unstable steady state.

\section{Stabilization for the linearized system}

Theorem 4.1. Assume that $\left(\mathrm{ye}_{\mathrm{e}}, \mathrm{ze}_{\mathrm{e}}\right)$ is unstable, then there exists $\mathrm{V}:[0, \infty) \rightarrow \mathrm{R}^{2}$ such that

$\mathrm{du}$

$$
\mathrm{dt}^{\mathrm{A}}=\mathrm{Au}+\mathrm{BV}, \quad-\mathrm{u}(0)=\mathrm{u} 0,
$$

is exponentially stable at $\left(\mathrm{ye}_{\mathrm{e}}, \mathrm{ze}_{\mathrm{e}}\right)$, where

$\mathrm{V}=-\mathrm{R}^{-1} \mathrm{~B}^{*}$ Пu.

Here $\Pi$ satisfies the Riccati equation

$\mathrm{A}^{*} \Pi+\Pi \mathrm{A}-\Pi \mathrm{BB}{ }^{*} \Pi+\mathrm{Q}=0$,

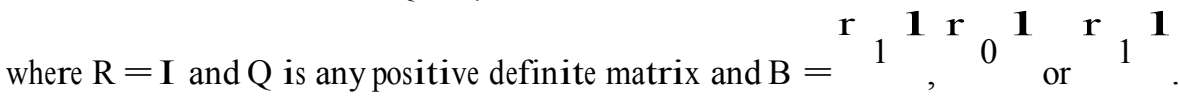

$0 \quad 1 \quad 1$

Further there exists $\rho>0$, such that for all $\mathrm{u}_{0}: / \mathrm{u}_{0} /<\rho$, there exist a unique solution $\mathrm{u} \in \mathrm{C}^{1}\left(0,+\infty, \mathrm{R}^{2}\right)$ such that, with some $\gamma>0, \mathrm{C}>0$,

$/ \mathrm{u}(\mathrm{t}) / \leq \mathrm{Ce}-\gamma \mathrm{t} / \mathrm{u} /$.

\section{Stabilization for the nonlinear system}

Theorem 5.1. Assume that ye $\quad \mathbf{r}$ is unstable. Then

$z_{\mathrm{e}}$

$\mathrm{V}=-\mathrm{R}^{-1} \mathrm{~B}^{*} \Pi^{\mathbf{r}} \mathrm{y}-\mathrm{ye}^{\mathbf{1}}, \mathrm{z}-\mathrm{ze}$

will stabilize exponentially the nonlinear system

dt $\quad z$

$\mathrm{d}^{\mathbf{r}} \mathrm{y}^{\mathbf{1}}=\underset{\mathrm{F}(\mathrm{y}, \mathrm{z}, \mathrm{z})}{\mathbf{r}}+\mathrm{BV}(\mathrm{t})$

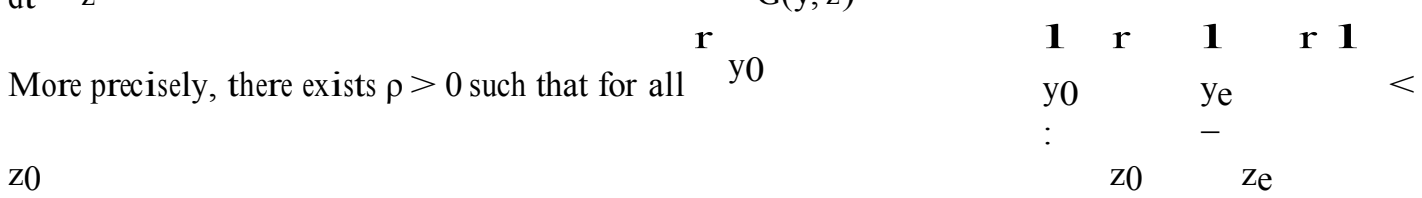

$\rho$, there exists a unique solution $\mathrm{y}$

$\bar{E}^{1}\left(0, \infty, R^{2}\right)$, such that, with some con-

stant $\mathrm{C}$ and $\gamma>0$,
stant $\mathrm{C}$ and $\gamma>0$
z0

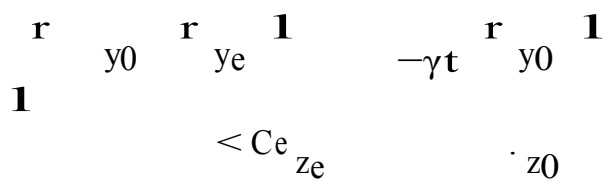

Consider 


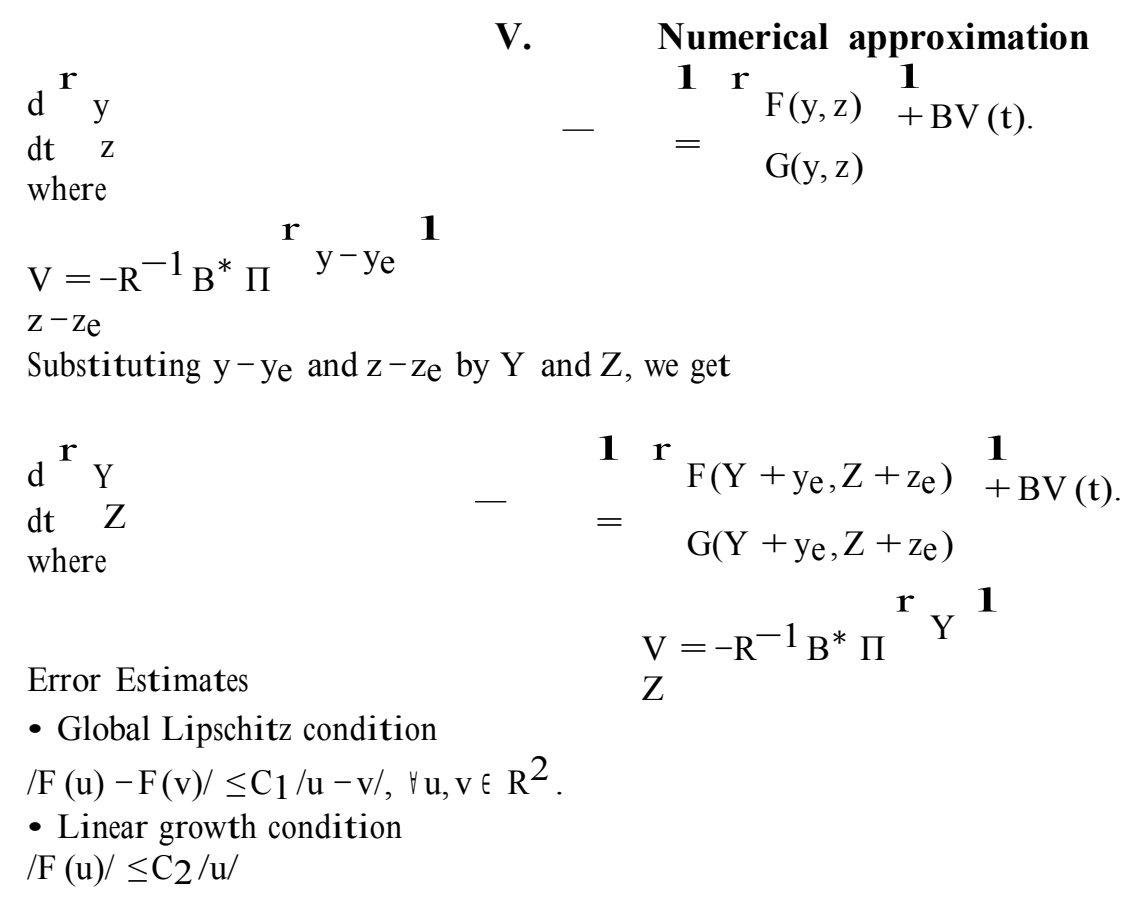

Theorem 6.1. Let $\mathrm{T}>0$. Assume that $\mathrm{F}$ satisfies the global Lipschitz condition and growth condition. Then there exists a constant $\mathrm{C}(\mathrm{T})$ such that, for any $q>0$,

$-0$

$/ \mathrm{U}^{\mathrm{n}}-\mathrm{u}\left(\mathrm{t}_{\mathrm{n}}\right) / \leq \mathrm{C}(\mathrm{T}) \mathrm{k}^{1}$

$/ \mathrm{u} 0 /$.

Proof [see Yan et al. (2009) for the detailed proof]

\section{Numerical Examples}

Four illustrating numerical examples of mathematical models of interacting pop- ulation systems which admit the classical notion of deterministic stabilization of their unstable steady-state solutions based on the theory and application of ([5]) have been considered. Four classical examples in which the unstable steady-state solutions were fully stabilized have been illustrated in the work of ([5]).

\section{Mathematical Formulation}

The model of competition between cowpea and groundnut legumes has the fol- lowing form

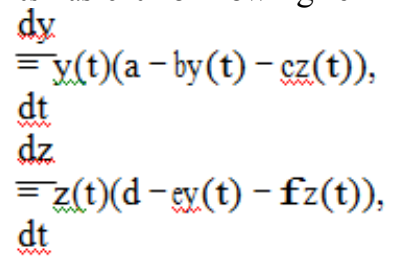

Here $y$ and $z$ denote the populations of the two legumes at time $t$. Here the nonnegative constants a and $d$ are called the intrinsic growth rates, $b$ and $\mathbf{f}$ are called the intra-species competitive parameters and the interspecies competitive parameters are represented by the constants $\mathrm{c}$ and $\mathrm{e}$.

8.1. Stability: Motivation for Stabilization. The above model equations have four steady states $\mathrm{y}=0$, $\mathrm{z}=0$,

$\mathrm{y}=0, \mathrm{z}=3.3534$,

$\mathrm{y}=3.2599$,

$\mathrm{y}=3.1908$,

$$
\begin{aligned}
& \mathrm{z}=0, \\
& \mathrm{z}=0.9543
\end{aligned}
$$

Here, $\mathrm{a}=0.0225, \mathrm{~b}=0.006902, \mathrm{c}=0.0005, \mathrm{~d}=0.0446, \mathrm{e}=0.01$, and $\mathrm{f}=0.0133$. In this example, the trivial steady-state solution is said to be unstable because its two positive eigenvalues are $\lambda_{1}=$ 0.0228 and $\lambda_{2}=0.0446$. Following the theory of stabilization ([5]), the trivial steady-state solution would 
need to be stabilized by constructing a controller which can drive this steady-state solution from the risk of extinction into stabiization. That is, over a long time interval, this controller will propel this steady-state solution to converge to the zero steady-state.

The first border steady-state solution $(0,3.3534)$ is unstable having two eigenval- ues of opposite signs $\lambda_{1}=-0.0446$ and $\lambda_{2}=0.0208$. Similarly, the second border

steady-state solution $(3.2599,0)$ is unstable having two eigenvalues of opposite signs

$\lambda_{1}=-0.0225$ and $\lambda_{2}=0.0120$. On the basis of the theory of stabilization, the

two border steady-state solutions would require to be stabilized. The unique pos-

itive steady-state solution otherwise called the co-existence steady-state solution $(3.1908,0.9543)$ is said to be stable having two negative eigenvalues $\lambda_{1}=-0.0234$ and $\lambda_{2}=-0.0113$. Although, the coexistence steadystate solution is stable, it would require a further stabilization which is a more challenging numerical deterministic stabilization problem which one can attempt to tackle. Having known that it is stable, it would be scientifically relevant to find out the extent of its stabilization for the purpose of planning and managing a cropcrop system. Not all crop-crop systems with these qualitative behaviour will interact and survive together. Fol- lowing [1], the cowpea and groundnut legumes will survive together having satisfied

the well established survival inequalities such as $\alpha 12=0.0724<0.9721=\underline{\mathrm{K}_{1}} \quad \mathrm{~K}_{2}$ and

$\alpha 21=0.7519<1.0287=\underline{\mathrm{K}_{2}} . \quad \mathrm{K}_{1}$

Next, the interaction between cowpea and groundnut can be defined using a

2-norm selection inter-specific model with the following deterministic precise pa- rameter values such as a $=$ $0.0225, \mathrm{~b}=0.0075, \mathrm{c}=0.02, \mathrm{~d}=0.0446, \mathrm{e}=0.1$ and $\mathrm{f}=0.0121$. The stability characterization of this model is displayed in the following Table

\begin{tabular}{|l|l|l|l|}
\hline Each Type of Steady-State Solution & \multicolumn{3}{|l|}{ Qualitative Stability Behaviour } \\
\hline Example & $\lambda 1$ & $\lambda 2$ & Stability \\
\hline$(0,0)$ & 0.0225 & 0.0446 & Unstable \\
\hline$(0,3.6860)$ & -0.0446 & -0.0512 & Stable \\
\hline$(3,0)$ & -0.0225 & -0.2554 & Stable \\
\hline$(0.3246,1.0033)$ & 0.0187 & -0.0333 & Unstable \\
\hline
\end{tabular}

Table 1. Calculation of the steady-state solutions for a 2-norm cowpea-groundnut interaction model

What do we learn from this Table 1? For this specific selected 2-norm cowpea- groundnut interaction model, we observe that this system has four steady-state solutions. From the theory of a steady-state solution ([1]), the trivial case and the coexistence case are said to be unstable and would need to be stabilized ([5]) whereas the two border steady-state solutions are said to be stable and hence will require a further stabilization. We also observe in this scenario that despite the fact that the cowpea and groundnut legumes will coexist together, these two legumes tend to go into the ecological risk of extinction because $\alpha 12=2.6667>0.8139=\underline{\mathrm{K} 1}$ and $\alpha_{21}=8.2645>1.2287=\underline{\mathrm{K}_{2}}$. This observation is not necessarily a counter- intuitive deduction in the sense of two likely intrinsic factors which may inhibit the survival of these two legumes. ${ }_{2}$ Firstly, the population size of cowpea in the coexistenck arrangement is 0.3246 which is far below the carrying capacity value of the cowpea hereby calculated to be 3 grams per square area while the the population size of groundnut in the coexistence arrangement is 1.0033 which is smaller than the carrying capacity value of groundnut having a calculated value of 3.6860 grams per square area. Secondly, the inhibiting effect of cowpea on the growth of groundnut which is 8.2645 is four times bigger than the inhibiting effect of groundnut on the growth of cowpea which is 2.6667 .

In another 2-norm selection model, we consider the following precise parameter values are $\mathrm{a}=0.0225, \mathrm{~b}$ $=0.0075, \mathrm{c}=0.004, \mathrm{~d}=0.0446, \mathrm{e}=0.002$, and $\mathbf{f}=0.0121$. In this scenario, the qualitative behaviour of stability is quite different from the previous example. Our contribution is displayed in the Table below:

\begin{tabular}{|l|l|l|l|}
\hline Each Type of Steady-State Solution & \multicolumn{3}{l|}{ Qualitative Stability Behaviour } \\
\hline Example & $\lambda 1$ & $\lambda 2$ & Stability \\
\hline$(0,0)$ & 0.0225 & 0.0446 & Unstable \\
\hline$(0,3.6860)$ & -0.0446 & 0.0078 & Unstable \\
\hline$(3,0)$ & -0.0225 & 0.0386 & Unstable \\
\hline$(1.1341,3.4985)$ & -0.0076 & -0.0432 & Stable \\
\hline
\end{tabular}

Table 2. Calculation of the steady-state solutions for another 2- norm cowpea-groundnut interaction model 
What do we learn from this Table 2? From this Table and without loss of generality, we observe that the trivial and the border steady-state solutions are said to be unstable while the coexistence steady-state solution is said to be stable. Therefore, the three unstable steady-state solutions in this context will require to be stabilized while the stable coexistence steady-state solution would need to be further stabilized in order to enhance an efficient ecosystem planning and management.

For the infinity-norm selection model, precise parameter values which we con- sidered are $\mathrm{a}=0.0225$, $\mathrm{b}=0.008065, \mathrm{c}=0.0045, \mathrm{~d}=0.0446, \mathrm{e}=0.0110$, and $\mathbf{f}=0.002$. In this scenario, the qualitative behaviour of stability is quite different from the previous example. Our contribution is displayed in the Table below:

\begin{tabular}{|l|l|l|l|}
\hline Each Type of Steady-State Solution & \multicolumn{3}{l|}{ Qualitative Stability Behaviour } \\
\hline Example & $\lambda 1$ & $\lambda 2$ & Stability \\
\hline$(0,0)$ & 0.0225 & 0.0446 & Unstable \\
\hline$(0,22.3)$ & -0.0446 & 0.0113 & Unstable \\
\hline$(2.7898,0)$ & -0.0225 & 0.0139 & Unstable \\
\hline$(2.1355,10.5549)$ & -0.0079 & -0.0305 & Stable \\
\hline
\end{tabular}

Table 3. Calculation of the steady-state solutions for $\infty$-norm cowpea-groundnut interaction model

Similarly, we observe from Table 3 that the trivial and the border steady-state solutions are unstable and will require constructing a controller to stabilize these three steady-state solutions. The unique positive coexistence steady-state solution is said to be stable and would only require a further stabilization ([5]). In this example, the cowpea and groundnut legumes will survive together ([1]) because

$$
\alpha 12=0.0620<0.1251=\underline{\mathrm{K}_{1}} \quad \mathrm{~K}_{2} \text { and } \alpha 21=5.5<7.9933=\underline{\mathrm{K} 2} \text {. }
$$

\section{Discussion of Results}

In these series of systematic literature reviews on other works which are related to the stabilization of unstable steady-states of interacting population systems, we have found several steady-state solutions which are unstable and hence would require to construct a controller which can be utilized to stabilize them. The stable steady-state solutions can also be further stabilized.

\section{Concluding Remarks and Further Research}

The idea of stabilizing a mathematical model of interacting population systems can be extended to determine the delayed stabilization of a mathematical model of two interacting legumes such as cowpea and groundnut in a deterministic sense. The practical realization of this crucial application in agriculture will be the focus of our next presentations.

\section{References}

[1] E.N. Ekaka-a, Computational and Mathematical Modelling of Plant Species Interactions in a Harsh Climate, PhD Thesis, Department of Mathematics, The University of Liverpool and The University of Chester, United Kingdom, 2009.

[2] N.J. Ford, P.M. Lumb, E. Ekaka-a, Mathematical modelling of plant species interactions in a harsh climate, Journal of Computational and Applied Mathematics 234, (2010), 2732-2744.

[3] N.J. Ford, S.J. Norton, Noise-induced changes to the behaviour of semi-implicit Euler methods for stochastic delay differential equations undergoing bifurcation, Journal of Computational and Applied Mathematics 229, (2009), 462-470

[4] T.A. Troost, B.W. Kooi, S.A.L. M. Kooijman, Bifurcation analysis of ecological and evolu- tionary processes in ecosystems, Ecological Modelling 204, (2007), 253-268.

[5] Yubin Yan, Enu-Obari N. Ekaka-a, Stabilizing a mathematical model of population system, Journal of the Franklin Institute 348, (2011), 2744.-2758. 